Research Article

\title{
Determinants of Healthcare Expenditure in Eastern Uttar Pradesh, India: Through the lens of NSSO Data
}

\author{
Manokamana Ram', Ajay Kumar ${ }^{2}$
}

${ }^{1}$ Assistant Professor, ${ }^{2}$ Research Assistant, Department of Economics, Banaras Hindu University, Varanasi, Uttar Pradesh, India. DOI: https://doi.org/10.24321/0019.5138.202147

\section{I $\quad \mathbf{N} \quad \mathbf{F} \quad \mathbf{O}$}

\author{
Corresponding Author: \\ Manokamana Ram, Department of Economics, \\ Banaras Hindu University, Varanasi - 221005 , \\ Uttar Pradesh, India. \\ E-mail Id: \\ manuecobhu@gmail.com \\ Orcid Id: \\ https://orcid.org/0000-0002-0689-4928 \\ How to cite this article: \\ Ram M, Kumar A. Determinants of Healthcare \\ Expenditure in Eastern Uttar Pradesh, India: \\ Through the lens of NSSO Data. J Commun Dis. \\ 2021;53(3):118-126.
}

Date of Submission: 2021-07-19

Date of Acceptance: 2021-09-03

\section{$\begin{array}{llllllll}\mathbf{A} & \mathbf{B} & \mathbf{S} & \mathbf{T} & \mathbf{R} & \mathbf{A} & \mathbf{C} & \mathbf{T}\end{array}$}

\begin{abstract}
This study aims to examine the determinants of health-care expenditure in the Eastern region of Uttar Pradesh. Secondary data from the National Sample Survey Office (NSSO) of 75th round on social consumption related to health were utilized. The Heckman two-step selection model was used to analyse household and individual decisions to seek care. Findings of this study reveal that having household head aged between 31 to 60 and above 60 years, household size greater than 5 members, belonging to religion other than Hindu, non-ST category as Schedule caste, Other backward class and others, people residing in urban area, people having higher economic status, private hospitals, upper primary and secondary+ schooling of household head and having household members with chronic illnesses were determinants contributing more health-care spending. However, female household head had less likely to incur healthcare expenditure as compared to male household in the region. An important finding indicates that the majority of people visited private hospitals in the region which increased the health-care spending at large and it burdened financially to the vulnerable section of the society. Based on the discussion, a few policy suggestions have been proposed to counter the above problems.
\end{abstract}

Keywords: Determinants, Healthcare, Expenditure, Eastern, Uttar Pradesh, NSSO

\section{Introduction}

During the post reform era, India experienced substantial economic and agricultural growth, resulting in rising incomes and aggregate food self-sufficiency. Despite these merits, India's demographic and health indicators continue to lag behind, with low life expectancy (69 years), prevalence of infectious \& communicable diseases, high maternal \& child mortality rate (almost 37 per 1,000 lives), high fertility coupled with a young age structure and increased urbanization. ${ }^{51}$ Economic survey 2019 depicts that, "Access to healthcare is still a major challenge in India. If India's hospital facilities remain at current levels, rising population over the next two decades (even with slowing population growth rates) will sharply reduce the per capita availability of hospital beds in India across all major states" which we have been witnessing in this COVID-19 period. It adds that many states like Madhya Pradesh, Uttar Pradesh, Bihar, Rajasthan and Odisha have poorly manned primary 
health centres and witness more number of mother and child deaths.

Normally, health is a priority sector of government activities. Economic growth is greatly affected by health as its impact is obvious on human capital accumulation. ${ }^{11,51}$ We have evidences that efficiency of healthy people is higher compared to that of those who are less healthy or ill. A greater amount of wealth is accumulated by healthy people due to their improved work abilities. ${ }^{2}$ That is why a higher budgetary allocation on health expenditure is needed in any country. One of the major determinants of budget allocation on health sector is the prevailing socio-economic conditions of the country. Among the socio-economic factors, the most important are education level and the coverage of national health programmes. Two other important factors are health infrastructure and health personnel. Verma CS, Usmani $\mathrm{G}^{7}$ in their study recommend a greater focus on the healthcare delivery mechanism in order to achieve higher rates of economic growth. Another important study ${ }^{22}$ has revealed that urbanization, education, crude birth rate and foreign aid are significant determinants of health expenditure.

Though most of the countries have to face multiple problems related to financing of their health systems, ${ }^{27}$ the worst hit are the low and middle-income countries (LMICs) like India. The health financing arrangements are skewed in such countries. It comes to observation that in these countries the level of protection against financial risk is a thin, healthcare services and non-affordable and the coverage of health-care services is small. We can attribute these to five A's i.e. Awareness Absence or the lack of awareness, Access Absence or the lack of access, Absence or crisis the manpower in healthcare, Adverse Affordability in terms of cost of healthcare and Absence or lack of Accountability. ${ }^{3}$ All these have been a cause of inefficient functioning of the Indian healthcare system and poor health outcomes. Moving closer to universal health coverage (UHC) ${ }^{53}$ as urged by World Health Assembly depends on the health financing arrangement of a country. In the context of above mentioned scenario, the aim of present study i.e. to gain a deeper understanding of the determinants contributing to health-care spending among households in India, particularly, in eastern Uttar Pradesh (U.P.) becomes really important. This will impart new knowledge to enable policy makers and political actors to act for the improvement of the noted determinants. This study is an attempt to analyses the extent of healthcare spending and its determinants among households in India, particularly, in eastern U.P. It is important to note that a number of studies in different countries have analysed the determinants of healthcare spending. $6,10,12,22,41,44,45,47-49,54$ The findings of these studies have revealed that the determinants of health expenditure among households include education, household size, chronic illness, income, age structure of population, residence, gender, weight, employment, population density, insurance coverage, life expectancy, population per primary healthcare centre, population per doctor, urbanization, crude birth rate, foreign aid, fiscal capacity, state's priority to health, political participation and lifestyle.

However, there is dearth of evidences on healthcare spending determinants at the household level in India using NSSO (National Sample Survey Office) data. One such study is "Determinants of Public Expenditure on Health in India: The Panel Data Estimates". This study used data sets of Finance Account of individual states and of RBI-State Finance. The main findings were that policy reforms initiated in 2005, fiscal capacity and people's political participation in a particular state had significant positive influence on government health expenditure. Another study ${ }^{41}$ revealed that demographic factors have less impact on spending. Verma CS et al. ${ }^{49}$ have concluded that the likelihood of selecting a public provider for hospitalization care was 4.8 times higher in the poorest quintile and 3.4 times as high for women. Since, people go untreated in absence of adequate access to public sector services; this factor may be responsible for an apparently higher proportion of utilisation of healthcare services of private sector in data. The main difference of our study from the previous studies is on the determinants of healthcare expenditure in eastern region of U.P. The present study uses the NSSO data set and the Heckman two-step 'selection model'.6,25 The study provides evidence and makes significant contribution to the scarce literature on determinants of healthcare expenditure in eastern U.P. and presents implications of the same for health policy in respect of universal health coverage. This study hypothesizes that individual and household characteristics are not significant determinants of healthcare spending in eastern UP, India.

\section{Overview of the Indian Health-care System in General and Eastern Uttar Pradesh in Particular}

With a population of more than 1.2 billion, India is the world's largest democracy. With the rapid economic growth over the decade, the country has witnessed increased integration with the global economy and has emerged as a global player. ${ }^{52}$ Being world's third largest economy in terms of purchasing power parity the country aspires to become a high-middle income country by 2030.52 However, on comparing the country with other countries that had witnessed almost similar level of economic development at the time of independence, the burden of preventable disease in India remains higher and healthcare remains far away from being equitable, accountable, or affordable. ${ }^{38}$ Indian healthcare system is a complex mix of private hospitals operating as enterprises under a free market and public hospitals which operate under government control with staff salaries paid by government and all buildings and 
equipment owned by government. According to National Family Health Survey-3, private sector accounts for almost $70 \%$ of health-care services in urban area and $63 \%$ in rural India viz-a viz the public health sector which accounts for only $30 \%$ of health-care services in urban area and $37 \%$ in rural India.

The three categories of healthcare delivery mechanism in India, classified under three categories- primary, secondary and tertiary care, are meant to work together for ensuring smooth delivery of healthcare. However, duplication of responsibilities among these three has resulted in poor coordination. Crippling with a number of challenges like decaying and poor infrastructure, poor governance, less budgetary allocation, poor service delivery and poor performance of health workers, the primary healthcare system which is supposed to be the foundation of country's health system, has miserably failed to provide basic healthcare services to Indian population. ${ }^{17}$ The health indicators for India are poorer when compared to the average for South Asia on similar indicators. India has a life expectancy of 69 years, under-5 mortality rate at 37 per 1000 live births, maternal mortality ratio at 145 per 100,000 live births and neonatal mortality rate at 23 per 1000 live births. The health financing and expenditure indices also reveal that total health expenditure in India is only $1.6 \%$ of GDP while public expenditure on health as a percentage of total health expenditure is only $27.13 \%$ and, private expenditure on health as a percentage of total health expenditure is $72.06 \% .^{52}$

In addition to the above mentioned facts, we know that Uttar Pradesh is among the poorest states in India. It not only accounted for $39.8 \%$ of its population living below the poverty line in $2011-12^{35}$ but also had worst performance on health indices with a high infant mortality rate (43 per 1,000 live births) ${ }^{8}$ and high maternal mortality ratios (201 per 1,00,000 live births as of 2014-16). There is a dire need in Uttar Pradesh to remove financial barriers in its way of accessing healthcare services and reconstructing a healthcare system that provides greater financial protection against the costs of healthcare. However, observations from 75th round of NSSO (July 2017 to June 2018) reveal that burden of average healthcare expenditure on people of U.P. is far greater in comparison of the similar average at India level. ${ }^{31}$ The average total medical expenditure per hospitalization case in U.P. is Rs. 26089 as against Rs. 20135 in India. The average total medical expenditure per hospitalization case in rural and urban areas of the Uttar Pradesh is Rs. 23144 and Rs. 33339 as against Rs. 16676 and Rs. 26475 in the rural and urban areas of the country respectively.

NSSO has divided Uttar Pradesh into NSS regions as Northern upper Ganga plains, Central, Eastern, Southern, and Southern upper Ganga plains. The region of eastern Uttar Pradesh consists of 18 districts. Compared to female population, the male population in the state is higher with a percentage ranging between $53.6 \%$ and $50.5 \%$. Sex ratio in eastern Uttar Pradesh districts ranges between 1020 and 867 while literacy ranges from $66.1 \%$ to $35.2 \%$. Demographic analysis of the area reveals that share of working population in the districts of eastern region ranges between $28.5 \%$ and $39.4 \%$.

Workers in this area are engaged in different occupations. By occupation workers are classified as cultivators, agricultural labourers, worker in household industry and other workers. The share of cultivator varies between $59.7 \%$ and $21.1 \%$, the share of agricultural labourers ranges between $40.1 \%$ and $10.4 \%$ while the share of workers in households' industry ranges between $22.6 \%$ and $2.2 \%$. This is indicative of cottage and household industry based economic activity (Upadhyay \& Upadhyay, 2011). Moreover, the average total medical expenditure per hospitalization in case of Eastern U.P. is Rs. 22422 as against Rs. 26089 in overall U.P. This low health status as compared to all-India and at U.P. must be inquired, hence, the present study tries to find out determinants of healthcare expenditure in eastern U.P.

\section{Materials and Methods}

\section{Data Source}

The present study has used secondary data from the NSSO. In India, NSSO carries out surveys on socio-economic, demographic, agricultural and industrial subjects to collect households and enterprises data from villages and towns. NSSO acts as focal agency of the Govt. of India for collection of vital statistical data for developmental planning. Its 75th round on social consumption related to health, forms a vital source of primary data on the subject for the country. The survey has come out with basic information on the health sector by providing data on morbidity, ailments and treatment profiles, role of private sector as well as of government in healthcare provisions, expenditure on medicines, medical consultation, investigation, hospitalization expenditure, maternity, childbirth and the condition of the aged etc. A stratified multi-stage design was adopted for the 75th round survey and the survey covered the entire Indian union government (except for those villages in Andaman and Nicobar Islands, which are difficult to access), where data were collected from $1,13,823$ households.

\section{Data Collection}

For the purpose of the study, data was extracted from NSSO 75 th round on social consumption related to health using STATA 14. Only 10 variables relevant to the objectives of the study were selected. 


\section{Variables Measurement Dependent Variable}

The dependent or outcome variable in this study was healthcare spending/medical expenditure. It comprised of all the expenditure spent on health and medical care for availing all health facilities by individuals in the household. The expenditure by individuals on health \& medical care includes package components, consultation fees, medicines, bed charges, diagnostic tests and other medical expenditure on traditional/alternative medicines. Healthcare expenditure for preventive and curative care both is a continuous variable and to estimate the same, questions were asked about amount paid for bed charges, doctor's/surgeon's fees, total amount paid for medicines, diagnostic tests, attendant charges, physiotherapy, personal medical appliances, and blood, oxygen, etc. ${ }^{31}$

\section{Independent Variables}

Grossman's theory of the demand for health, ${ }^{16}$ Andersen's Behavioural Model, ${ }^{1}$ and a literature review on the determinants of health care expenditure ${ }^{6,10,12,22,37,41,44,45,47,49,54}$ were used as a guide for the independent or explanatory variables. According to Grossman $\mathrm{M},{ }^{16}$ factors such as age, wage rate, and education influence the demand for health and healthcare. In his model, he proposes that the demand for health may be viewed as a durable capital stock that produces an output of healthy time. Using supply and demand curves for health capital, the model provides an explanation for variations in healthcare among persons. Grossman's model predicts that if the rate of depreciation increases with age, after some point in the life cycle, the quantity of health capital demanded would decline over the life cycle. The model of demand for health also enables one to analyse the effects of demographic variables like age, wage rate, and education without assuming that these variables are positively or negatively correlated with consumers' "tastes" for health. ${ }^{16}$ The Andersen Behavioural Model, categorises the variables determining individual's decision to seek health-care into: predisposing factors (age, sex, ethnicity, and household head characteristics); enabling factors (location, geo-political zone, education, health insurance status, and household income); and need factors (perceived severity of illness, self-reported health status, presence of physician diagnosing chronic diseases, and overweight).

It is the interaction of these factors that determines whether or not an individual will seek healthcare. In our study, education of household head was classified into five groups' viz. no schooling, below primary, primary, upper primary, and secondary, age was categorized into three groups and gender (sex) of household head was categorized into male and female. Household size was defined as the number of individuals in a household, and was re-coded in two categories i.e. less than five members and more than five members. Place of residence (location) was classified into urban and rural areas where urban residents were defined as households living in towns and urban neighbourhoods of cities, while rural residents were defined as households living in villages and suburban areas of the cities. Religion was grouped into two categories Hindu and others, while, social group was defined according to the survey questionnaire, and grouped into four categories as ST, SC, $\mathrm{OBC}$ and Others. Further, economic status was defined as poor, middle and richest, however, chronic ailments was divided in two groups 'no' and 'yes'. For the purpose of study, Medical institutions were defined according to the survey questionnaire, and categorized into government/ public hospital, charitable and private hospital.

\section{Research Tool}

Since, estimation of the determinants of healthcare spending from the sub-population who consulted health practitioners for treatment may have introduced bias, we applied the Heckman 'two-step' selection model, ${ }^{55}$ as used in earlier studies ${ }^{6}$ to address the issue of selection bias among individuals who did not report paying for healthcare. The Heckman 'two-step' selection model checks potential sample selection bias. ${ }^{54}$ Using the regression equation (i) and selection equation (ii) in the model:

$y_{j}=x_{j} \beta+u_{j} j$

Health-care spending was not always observed. Rather, health-care spending for households who fell sick and sought health-care services was observed if:

$z_{j} \gamma+u_{2} j>0$

Where,

$* u_{1} \sim N(0, \sigma)$

$* u_{2} \sim N(0,1)$

$*$ corr. $\left(u_{1}, u_{2}\right)=\rho$

When $\rho \neq 0$, the application of standard regression techniques to the first equation yields biased results. However, use of Heckman model provides consistent, asymptotically efficient estimates for all the parameters in such cases (Heckman 1979). We also checked the model for presence of multi-collinearity and assessed the goodness of fit using the Hosmer-Lemeshow test.

\section{Results and Discussion}

Table 1 presents the determinants of health expenditure by regression and Two-step Heckman selection model. In the regression model, household heads with age between 31 to 60 years $(0.14, p=0.54)$ and above 60 years $(0.13, p=0.61)$, household size greater than five members $(0.17, p=0.18)$ and religion other than Hindu $(0.10, p=0.52)$ were found 
more likely to incur health-care spending in comparison to their reference categories, but the relation was not found significant. As per the regression, Social group of patient is a potential determinant of expenditure on healthcare as Schedule caste $(1.48, p=0.01)$, other backward class (1.27, $p=0.01)$, and others $(1.47, p=0.01)$ were found to incur more expenditure on health care than their counterpart. Place of residence had positive association with health care expenditure as urban residents $(0.01, p=0.95)$ were found more likely to incur health care expenditure in comparison to rural residents. Economic status of the households also had great association with expenditure on health. Regression shows that middle income households $(0.48$, $p=0.00)$ and richest households $(0.5, p=0.00)$ were incurring more expenditure on health care in comparison to poor households. Gender wise findings revealed that female household heads were $(-1.12, p=0.45)$ less likely to incur expenditure on healthcare in comparison to male household heads. Further, household heads with upper primary and Secondary+ schooling of $(0.27, p=0.07)$ were likely to incur significantly more expenditure on health care compared to household heads with no schooling. As was expected, households having members with chronic illness $(0.16$, $\mathrm{p}=0.25$ ) had more health care spending in comparison to the reference category. Private hospitals $(1.22, p=0.00)$ were also found likely to incur more healthcare expenditure than government and charitable hospitable.

Table I.Determinants of Health-care Expenditure by Regression and Two-step Hackman Selection Model

\begin{tabular}{|c|c|c|c|c|}
\hline \multirow{2}{*}{$\begin{array}{c}\text { Variable } \\
\text { Household head age }\end{array}$} & \multicolumn{2}{|c|}{ Regression } & \multicolumn{2}{|c|}{ Heckman Selection Model } \\
\hline & Coef. (Std. error) & P-value & Coef. (Std. error) & P-value \\
\hline \multicolumn{5}{|l|}{$<31$ years $^{\circ}$} \\
\hline 31 to 60 years & $0.14(0.23)$ & 0.54 & $1.07^{* * *}(0.32)$ & 0.00 \\
\hline$>60$ years & $0.13(0.25)$ & 0.61 & $1.09 * *(0.4)$ & 0.01 \\
\hline \multicolumn{5}{|c|}{ Household size } \\
\hline \multicolumn{5}{|l|}{$<=5^{\circledR}$} \\
\hline$>5$ & $0.17(0.12)$ & 0.18 & $-0.38(0.27)$ & 0.16 \\
\hline \multicolumn{5}{|c|}{ Religion } \\
\hline \multicolumn{5}{|c|}{ Hindu $^{\circ}$} \\
\hline Others & $0.10(0.15)$ & 0.52 & $-0.21(0.31)$ & 0.50 \\
\hline \multicolumn{5}{|c|}{ Social group } \\
\hline \multicolumn{5}{|c|}{$\mathrm{ST}^{\circ}$} \\
\hline SC & $1.48 * *(0.52)$ & 0.01 & $0.88(0.63)$ & 0.16 \\
\hline $\mathrm{OBC}$ & $1.27 * *(0.51)$ & 0.01 & $1.05 *(0.62)$ & 0.09 \\
\hline Others & $1.47^{* *}(0.52)$ & 0.01 & $1.28 *(0.67)$ & 0.06 \\
\hline \multicolumn{5}{|c|}{ Place of residence } \\
\hline \multicolumn{5}{|l|}{ Rural $^{\circledR}$} \\
\hline Urban & $0.01(0.13)$ & 0.95 & $0.70 * *(0.35)$ & 0.04 \\
\hline \multicolumn{5}{|c|}{ Economic status } \\
\hline \multicolumn{5}{|l|}{ Poor $^{\circledR}$} \\
\hline Middle & $0.48^{* * *}(0.14)$ & 0.00 & $0.23(0.31)$ & 0.45 \\
\hline Richest & $0.5^{* * *}(0.16)$ & 0.00 & $-0.34(0.35)$ & 0.33 \\
\hline \multicolumn{5}{|c|}{ Sex (household head) } \\
\hline \multicolumn{5}{|l|}{ Male $^{\circledR}$} \\
\hline Female & $-0.12(0.15)$ & 0.45 & $-1.41 * * *(0.27)$ & 0.00 \\
\hline \multicolumn{5}{|c|}{ Schooling (household head) } \\
\hline \multicolumn{5}{|l|}{ No schooling ${ }^{\circledR}$} \\
\hline Below primary & $-0.05(0.24)$ & 0.84 & $-1.11^{* *}(0.4)$ & 0.01 \\
\hline
\end{tabular}




\begin{tabular}{|c|c|c|c|c|}
\hline Primary & $-0.01(0.17)$ & 0.94 & $-0.68^{* *}(0.33)$ & 0.04 \\
\hline Upper primary & $0.18(0.18)$ & 0.31 & $0.06(0.41)$ & 0.88 \\
\hline Secondary + & $0.27^{*}(0.15)$ & 0.07 & $-0.37(0.33)$ & 0.26 \\
\hline \multicolumn{5}{|c|}{ Chronic ailment } \\
\hline \multicolumn{5}{|c|}{ No $^{\circ}$} \\
\hline Yes & $0.16(0.14)$ & 0.25 & $-0.15(0.31)$ & 0.63 \\
\hline \multicolumn{7}{|c|}{ Medical institution } \\
\hline \multicolumn{7}{|c|}{ Govt./public hospital } \\
\hline Charitable & $0.26(0.35)$ & 0.45 & $-0.31(0.47)$ & 0.52 \\
\hline Private hospital & $1.22^{* * *}(0.12)$ & 0.00 & $1.36^{* * *}(0.26)$ & 0.00 \\
\hline Number of observations & 522 & 566 & \\
\hline
\end{tabular}

${ }^{*}$ significant at $p<0.1,{ }^{* *}$ significant at $p<0.05,{ }^{* * *}$ significant at $p<0.01,{ }^{\circledR}$ Reference category.

In the selection model, household heads having age between 31 and 60 years $(1.07, p=0.00)$ and above 60 years $(1.09, p=0.01)$ were found more likely to incur expenditure on healthcare. Households with other backward category $(1.05, p=0.09)$ and others $(1.28, p=0.06)$ were also more likely to incur expenditure on healthcare in comparison to the reference category. As in the regression model, in selection model too, Social group of patient has been found a potential determinant of expenditure on healthcare. Schedule caste $(0.88, p=0.16)$, other backward class $(1.05$, $p=0.09)$, and others $(1.47, p=0.01$ ) were found to incur more expenditure on health care than their counterpart. Place of residence had positive association with healthcare expenditure. Households in the category urban residents $(0.70, p=0.04)$ were more likely to incur expenditure on healthcare compared to those in the category rural residents. When compared to male household heads, female household heads $(-1.41, p=0.00)$ were less likely to incur expenditure on health care. Households with upper primary schooling $(0.06, p=0.88)$ were more likely to incur expenditure on healthcare. Medical treatment in private hospitals $(1.36, p=0.00)$ was also likely to incur more healthcare expenditure as in the regression model.

\section{Discussion}

The findings of our study reveal that household and individual characteristics play an important role in variations of the likelihood of health-care spending. In the present study, household heads of age between 31 to 60 years $(0.14, p=0.54)$ and above 60 years $(0.13, p=0.61)$ have shown increased likelihood of healthcare expenditure. This could be the result of more awareness programme introduced by government recently and older population, which may contribute to the rising costs of healthcare. This finding is supported by studies conducted in OECD countries, ${ }^{45}$ Bangladesh, ${ }^{44}$ Spain ${ }^{10}$ but it is in contrast with studies from Malaysia, ${ }^{25}$ Iran $^{55}$ and WHO, ${ }^{54}$ which show that households with members aged 65 years and above either have no impact or significant negative impact on healthcare expenditure. Present study reveals that household size greater than five members $(0.17, p=0.18)$ increased the likelihood of healthcare expenditure. A possible explanation for this may be that households with family size of more than five members have less resources on an average and cannot afford to pay for health care as much as those households which have a family size of five or less members. This finding is consistent with studies from America (Halliday et al., 2009) ${ }^{57}$ and Nepal ${ }^{19}$, where household size was found significantly associated with health-care spending. Households belonging to religion other than Hindu ( 0.10 , $\mathrm{p}=0.52)$ or to a non-ST category i.e. schedule caste (1.48, $p=0.01)$, Other backward class $(1.27, p=0.01)$, or others $(1.47, p=0.01)$, those residing in urban area $(0.01, p=0.95)$ and those having higher economic status like middle income households $(0.48, p=0.00)$ and richest households $(0.5$, $p=0.00$ ) were found to be spending significantly higher on healthcare than their counterparts. The findings of the study also revealed that households belonging to the lower socio-economic status (Hindu religion, rural people, ST category and Poor income household) had been constantly experiencing poor health outcomes. Inability to have access to healthcare facilities or to pay for the use of healthcare services may be a reason for this. These findings were supported by the studies carried out by Dwivedi $R$, and Pradhan J, ${ }^{56}$ Prinja S et al., ${ }^{36}$ Mills A et al. ${ }^{28}$ and Cissé B et al. ${ }^{9}$

Further, present study revealed that private hospitals (1.22, $p=0.00$ ) were more likely to incur healthcare expenditure than government and charitable hospitals. It is noted that public hospitals have to face multiple challenges like deficiency of skilled staff, improper or inadequate infrastructure, unmanageable patient load and poor or average quality of services, therefore public moves towards private hospitals for treatment. It has also been noted that people who use the services of private hospitals have the suspicion that many private providers of health care perform 
unnecessary diagnostic tests and surgical procedures. However, despite this suspicion, people are yet choosing the private sector in overwhelming numbers since the public alternative is much worse with interminable waits in dirty surroundings with hordes of other patients. Many medicines and tests are also not available in the public sector, so patients have to go to private shops and laboratories to avail the healthcare. Owing to these reasons private hospitals were found more likely to incur health care expenditure in this region. This result is supported by the studies carried out by Mohsin $M,{ }^{29}$ Kruse FM et al., ${ }^{26}$ Bel G \& Esteve $M,{ }^{5}$ Bajpai $V^{50}$ and Sengupta A. ${ }^{40}$

As per the findings, female household heads $(-1.12, p=0.45)$ were less likely to incur expenditure on health care as compared to their male counterparts. This may be attributed to the greater ability of female-headed households to take proper health precautions and increasing rate of female literacy in this region in recent years. This result is consistent with the studies of Azzani M et al., ${ }^{4} \mathrm{Pal} R \mathrm{R}^{34}$ Okunade AA et al. ${ }^{32}$ but it is inconsistent with the studies of Htet $\mathrm{S}$ et al. ${ }^{20}$ and Fan $\mathrm{L}$, Habibov NN ${ }^{14}$ where gender of the head of household was found to be a non-significant factor. However, the study revealed that household heads with schooling levels upper primary and secondary $(0.27$, $p=0.07$ ) were likely to incur significantly more expenditure on healthcare than the household heads with no schooling. A possible explanation is that as a person becomes more educated, he becomes more knowledgeable and possesses more information about better healthcare options at his command. This result is similar to studies in Myanmar ${ }^{24}$, African Country, ${ }^{33}$ Thailand ${ }^{32}$ and Burkina Faso ${ }^{47}$ but it is in contrast with the studies from Bangladesh ${ }^{44}$ and Nepal. ${ }^{19}$

Lastly, households having members with chronic illness $(0.16, p=0.25)$ had increased health care spending when compared to the reference category. An appropriate explanation for this is that cost of managing chronic illnesses is higher in comparison to the cost of managing non-chronic illnesses. This finding is similar to study in Myanmar, ${ }^{24}$ Bangladesh, ${ }^{37} \mathrm{China}^{43}$ and Zambia. ${ }^{18}$ The study also found that the type of illness suffered by households is an important determinant of healthcare spending.

\section{Conclusion and Policy Implication}

Although some studies have been conducted on determinants of healthcare expenditure in general, there is still dearth of research on it for the eastern region of Uttar Pradesh. In this study, we have examined the determinants of healthcare expenditure in the Eastern region of Uttar Pradesh with the help of Heckman 'two-step' selection model. Our findings suggest that individual and household characteristics increases and decreases the risk of incurring healthcare spending. Female household heads are less likely to incur healthcare expenditure. Further, the study indicated that households belonging to the lower socioeconomic status (Belongs to Hindu religion, rural people, ST - category and poor income household) were constantly experiencing poor health outcomes. This is due to the fact that these people have minimum access to healthcare facilities or they are not in a position to pay for the use of healthcare services on frequent basis. Moreover, the majority of people visited private hospitals in the region which increased the healthcare spending and ultimately it burdened financially to the vulnerable section of the society. Hence, policy makers and political actors need to stop the high reliance on private healthcare facilities by increasing public health expenditure at length and more focus must be given on female education in the region.

\section{Acknowledgement}

This work is supported by Indian Council of Social Science Research (Ministry of Human Resource Development), Aruna Asaf Ali Marg, New Delhi - 110067, India.

\section{Source of Funding}

I am thankful to ICSSR for funding such an important issue.

\section{Conflict of Interest: None}

\section{References}

1. Aday LA, Andersen RM. A framework for the study of access to medical care. Health Serv Res. Fall 1974;9(3):208-20. [PubMed] [Google Scholar]

2. Jerome A, Tarani C, Micheal M. Socio-economic status and health: causality and pathways. J Econom. 2003;112(1):57. [Google Scholar]

3. Kasthuri A. Challenges to healthcare in India - The five A's. Indian J Community Med 2018;43:141-3. [Google Scholar]

4. Azzani M, Roslani AC, Su TT. Determinants of household catastrophic health expenditure: a systematic review. Malays J Med Sci. 2019 Jan;26(1):15-43. [PubMed] [Google Scholar]

5. Bel G, Esteve M. Is private production of hospital services cheaper than public production? A metaregression of public vs. private costs and efficiency for hospitals. Int. Public Manag. J. 2019. [Google Scholar]

6. Aregbeshola BS, Khan SM. Out-of-pocket health-care spending and its determinants among households in Nigeria: a national study. J. Public Health. 2021;29:93142. [Google Scholar]

7. Verma CS, Usmani G. Relationship between health and economic growth in India. IJHD. 2019.

8. Census of India. Report on post enumeration survey. Office of the Registrar General and Census, Ministry of Home Affairs, Government of India. 2011.

9. Cissé B, Luchini S, Moatti JP. Progressivity and horizontal equity in health care finance and delivery: what about Africa? Health Policy. 2007 Jan;80(1):51-68. [PubMed] 
[Google Scholar]

10. Cantarero D, Lago-Penas S. The determinants of health care expenditure in Spain: A reexamination. XIV Encuentro De Economia Publica, 2007. [Google Scholar]

11. Bloom DE, Canning D. The health and wealth of nations. Science. 2000;287:1207-9.

12. Barik D, Desa S. Determinants of private healthcare utilisation and expenditure patterns in India. Munich Personal RePEc Archive (MPRA). 2017. Available from: https://mpra.ub.uni-muenchen.de/77220/ MPRA Paper No. 77220.

13. Upadhyay VK, Upadhyay SP. Demographic features in districts of Eastern Uttar Pradesh. The Indian Journal of Research Anvikshi, 2011.

14. Fan L, Habibov NN. Determinants of maternity health care utilization in Tajikistan: learning from a national living standards survey. Health Place. 2009 Dec;15(4):952-60. [PubMed] [Google Scholar]

15. Government of India. Economic Survey 2018-19. Government of India, Ministry of Finance, Department of Economic Affairs, Economic Division, New Delhi, India. 2019.

16. Grossman M. On the concept of health capital and the demand for health. J Polit Econ. 1972;8(2):223-55. [Google Scholar]

17. Health Care in India. Current state and key Imperative. Review of National Health Policy, 2015. Available from: https://assets.kpmg/content/dam/kpmg/in/ pdf/2016/09/AHPI-Healthcare-India.pdf.

18. Hjortsberg C. Why do the sick not utilise health care? The case of Zambia. Health Econ. 2003 Sep;12(9):75570. [PubMed] [Google Scholar]

19. Hotchkiss DR, Rous JJ, Karmacharya K, Sangraula P. Household health expenditures in Nepal: implications for health care financing reform. Health Policy Plan. 1998 Dec;13(4):371-83. [PubMed] [Google Scholar]

20. Htet S, Fan V, Alam K, Mahal A. Financial risks from ill health in Myanmar: evidence and policy implications. Asia Pac J Public Health. 2015 May;27(4):418-28. [PubMed] [Google Scholar]

21. Key indicators of social consumption in India: Health. Ministry of Statistics and Programme Implementation, Government of India. November 2019.

22. Toor IA, Butt MS. Determinants of health care expenditure in Pakistan. Pak. Eco. Soc. Rev. 2005;43(1):133-50. [Google Scholar]

23. Smits J. Estimating the Heckman two-step procedure to control for selection bias with SPSS. 2003. Available from: http://home.planet. $\mathrm{nl} / \sim_{\text {smits.jeroen. }}$

24. Khaing IK, Malik A, Oo M, Hamajima N. Health care expenditure of households in Magway, Myanmar. Nagoya J Med Sci. 2015 Feb;77(1-2):203-
12. [PubMed] [Google Scholar]

25. Khan HN, Razali RB, Shafie AB. Modelling determinants of health expenditures in Malaysia: evidence from time series analysis. Front Pharmacol. 2016 Mar;7:69. [PubMed] [Google Scholar]

26. Kruse FM, Stadhouders NW, Adang EM, Groenewoud $\mathrm{S}$, Jeurissen $\mathrm{P}$. Do private hospitals outperform public hospitals regarding efficiency, accessibility, and quality of care in the European Union? A literature review. Int J Health Plann Manage. 2018 Apr;33(2):e434-53. [PubMed] [Google Scholar]

27. Kutzin J. Health financing policy: a guide for decisionmakers (Health Financing Policy Paper). World Health Organization, Regional Office for Europe, Division of Country Health Systems, Copenhagen. 2008. Available from: http://www.euro.who.int/_data/ assets/pdf_ file/0004/78871/E91422.pdf. Accessed 5 February 2020.

28. Mills A, Ataguba JE, Akazili J, Borghi J, Garshong B, Makawia S, Mtei G, Harris B, Macha J, Meheus F, Mclntyre D. Equity in financing and use of health care in Ghana, South Africa, and Tanzania: implications for paths to universal coverage. Lancet. 2012 Jull;380(9837):126-33. [PubMed] [Google Scholar]

29. Mohsin M. Why people prefer private hospital over government hospital in Pakistan. Int. J. Curr. Res. 2018;10(5):69304-8.

30. National Family Health Survey (NFHS-3). Mumbai, India: International Institute for Population Sciences. 2005-06. Available from: http://rchiips.org/NFHS/nfhs3.shtml.

31. NSSO. Key Indicators of Social Consumption in India: Health. NSS KI (75/25.0). National Sample Survey Office, 2019. Available from: https://www.thehinducentre. com/resources/article7378862.ece.

32. Okunade AA, Suraratdecha C, Benson DA. Determinants of Thailand household healthcare expenditure: The relevance of permanent resources and other correlates. Health Econ. 2010 Mar;19(3):365-76. [PubMed] [Google Scholar]

33. Oluwatimilehin I. Determinants of household health care expenditure in an African country. Accessed December 26, 2014. Available from: http://dx.doi. org/10.2139/ssrn.2543002. [Google Scholar]

34. Pal R. Measuring incidence of catastrophic out-ofpocket health expenditure: with application to India. Int J Health Care Finance Econ. 2012 Mar;12(1):63-85. [PubMed] [Google Scholar]

35. Planning Commission (C. Rangarajan Committee Report). Report of the expert group to review the methodology for measurement of poverty. Government of India, New Delhi. 2014. Available from: http://www. indiaenvironmentportal.org.in/content/395787/reportof-the-expert-group-to-review-the-methodology-for- 
measurement-of-poverty-c-rangarajan-committeereport/.

36. Prinja S, Bahuguna P, Pinto AD, Sharma A, Bharaj G, Kumar V, Tripathy JP, Kaur M, Kumar R. The cost of universal health care in India: a model based estimate. PLoS One. 2012;7(1):e30362. [PubMed] [Google Scholar]

37. Rahman MM, Gilmour S, Saito E, Sultana $P$, Shibuya K. Health-related financial catastrophe, inequality and chronic illness in Bangladesh. PLoS One. 2013;8(2):e56873. [PubMed] [Google Scholar]

38. Reddy KS, Patel V, Jha P, Paul VK, Kumar AK, Dandona L; Lancet India Group for Universal Healthcare. Towards achievement of universal health care in India by 2020 : a call to action. Lancet. 2011 Feb;377(9767):760-8. [PubMed] [Google Scholar]

39. Little RJA. A note about models for selectivity bias. Econometrica. 1985;53(6):1469-74. [Google Scholar]

40. Sengupta A, Nundy S. The private health sector in India. BMJ. 2005 Nov;331(7526):1157-8. [PubMed] [Google Scholar]

41. Hooda SK. Determinants of public expenditure on health in India: The panel data estimates. Institute for Studies in Industrial Development (ISID), New Delhi. [Google Scholar]

42. Bushway $S$, Johnson $B D$, Slocum $L A$. Is the magic still there? The use of the Heckman two-step correction for selection bias in criminology. J Quant Criminol. 2007;23:151-78. [Google Scholar]

43. Shi W, Chongsuvivatwong V, Geater A, Zhang J, Zhang $H$, Brombal D. The influence of the rural health security schemes on health utilization and household impoverishment in rural China: data from a household survey of western and central China. Int J Equity Health. 2010 Feb;9:7. [PubMed] [Google Scholar]

44. Roy S. Determinants of healthcare expenditure on human capital and economic growth in Bangladesh: a longitudinal data analysis from 1995-2010. Asian J. Pharm. Res. Health Care 2014;6(1):6-10. [Google Scholar]

45. Nghiem SH, Connelly LB. Convergence and determinants of health expenditures in OECD countries. Health Econ Rev. 2017 Aug;7(1):29. [PubMed] [Google Scholar]

46. SRS Statistical Report. Office of the Registrar General \& Census Commissioner, India. Ministry of Home Affairs, Government of India. 2018.

47. Su TT, Pokhrel S, Gbangou A, Flessa S. Determinants of household health expenditure on western institutional health care. Eur J Health Econ. 2006;7(3):199-207. [PubMed] [Google Scholar]

48. Rahman T. Determinants of public health expenditure: some evidence from Indian states. Appl. Econ. Lett. 2008;15(11):853-7. [Google Scholar]
49. Verma CS, Singh S, Ranjan A, Sundararaman T. Social and systemic determinants of utilisation of public healthcare services in Uttar Pradesh. Economic \& Political Weekly 2018;45. [Google Scholar]

50. Bajpai V. The challenges confronting public hospitals in India, their origins, and possible solutions. Adv. Pub. Hea. 2014, 27 pages. [Google Scholar]

51. Jack W, Lewis M. Health investments and economic growth: an overview. Macroeconomic evidence and microeconomic foundations (The World Bank). [Google Scholar]

52. World Bank. World development indicators 2019. The World Bank, Washington, DC. 2019.

53. World Health Organization. Sustainable health financing, universal coverage and social health insurance. World Health Organization, Geneva. 2005. Available from: https://apps.who.int/iris/bitstream/ handle/10665/20383/WHA58_33-en.pdf? sequence=1. Accessed 5 February 2020.

54. Kea X, Saksenaa P, Holly A. The determinants of health expenditure: A country-level panel data analysis. World Health Organisation, 2011. Available from: https://r4d.org/wp-content/ uploads/TransisitionsInHealthFinancing_ DeterminantsofExpenditures.pdf. [Google Scholar]

55. Heckman J. Sample selection bias as a specification error. Econometrica. 1979;47(1):153-61. [Google Scholar]

56. Rezaei S, Fallah R, Karyani AK, Daroudi R, Zandiyan H, Hajizdeh M. Determinants of healthcare expenditures in Iran: evidence from a time series analysis. Med J Islam Repub Iran. 2016;30:313. [PubMed] [Google Scholar]

57. Dwivedi R, Pradhan J. Does equity in healthcare spending exist among Indian states? Explaining regional variations from national sample survey data. Int J Equity Health. 2017;16:15. [PubMed] [Google Scholar]

58. Halliday TJ, Park M. Household size, home health care, and medical expenditures. Working Papers 2009 16, University of Hawaii at Manoa, Department of Economics. [Google Scholar] 